\title{
Acquisition of Micro-mechanical Data on Irradiated Fuel
}

\author{
I.Zacharie-Aubrun $^{1}$, N. Payraudeau-Le Roux ${ }^{2}$, S. Meille ${ }^{2}$, Th. Douillard ${ }^{2}$, C. Langlois ${ }^{2}$ \\ 1. CEA, DEN, DEC Cadarache, 13108 St Paul Lez Durance, France \\ 2.INSA-Lyon, MATEIS CNRS UMR5510, F-69621 Villeurbanne, France
}

Modeling the nuclear fuel behavior during irradiation, including power ramp, requires knowing its mechanical properties. After base irradiation or transient tests, irradiated fuel is cracked radially and transversely. The fuel is thus divided into fragments of a few millimeters. Irradiated fuel is also porous with manufacturing pores and fission gas bubbles. Cracks and porosity of irradiated fuel don't allow conventional mechanical tests. That is why smaller specimens and micro-mechanical tests are being developed.

The CEA Cadarache bought an Auriga FIB SEM from Carl Zeiss (Figure 1) on which are mounted an EBSD Oxford and a removable in situ nano-indenter from CSM $(2 \mathrm{nN}-500 \mathrm{mN})$ in the chamber of the microscope. In addition, this microscope has been modified to examine the irradiated fuels.

Before this microscope is available in hot cells around mid-2015, tests are being developed on a "model" ceramic in the MATEIS INSA Lyon laboratory [1]. The tests presented in this document have been performed with a Carl Zeiss FIB SEM NVISION 40 and independent nano-indenter Agilent XPG200 $(50 \mathrm{nN}-500 \mathrm{mN})$.

The model material is cubic zirconia Technox 802 . Bending tests were conducted and its measured tensile stress was $170 \mathrm{MPa}$. The microstructure (grain size, porosity and crystalline structure) of this material is closed to the UO2 one, its hardness and toughness are higher than UO2. This material has the disadvantage of having a low electrical conductivity.

Zirconia was polished till diamond suspension 1 micron. Polishing is finished with a $0.06 \mu \mathrm{m}$ colloidal silica. The sample was then analyzed by EBSD. For this, it was tilted at $70^{\circ}$ and oriented to face the EBSD. The EBSD analysis allows the location of the grain boundaries without surface treatment.

A pillar was then manufactured by FIB with a beam of gallium (Figure 2). Before, a fine $13 \mathrm{~nm}$ carbon layer was deposed on the specimen to avoid charge problems. A large cavity was produced around the pillar with a diameter higher than the flat tip. Two pillars of different diameters were made : 1-2 microns and 5 microns. In the last step of the milling, the beam size was decreased to reduce the tapering of the pillar.

The pillar was compressed with a flat tip diameter of 10 microns, mounted on the Agilent nano-indenter (Figure 3). Both displacement and load were recorded.

These tests, developed on zirconia, will be hen performed on irradiated fuel when the microscope will be available in hot cell. 


\section{References:}

[1] N. Le Roux, Euromat 2013

[2] C. Niederbergeret al, Materials Science and Engineering A 527 (2010), p. 4306.

[3] N. Kheradmand, H. Vehoff, A. Barnoush, Acta Materialia V 61 (2013), p. 7454.

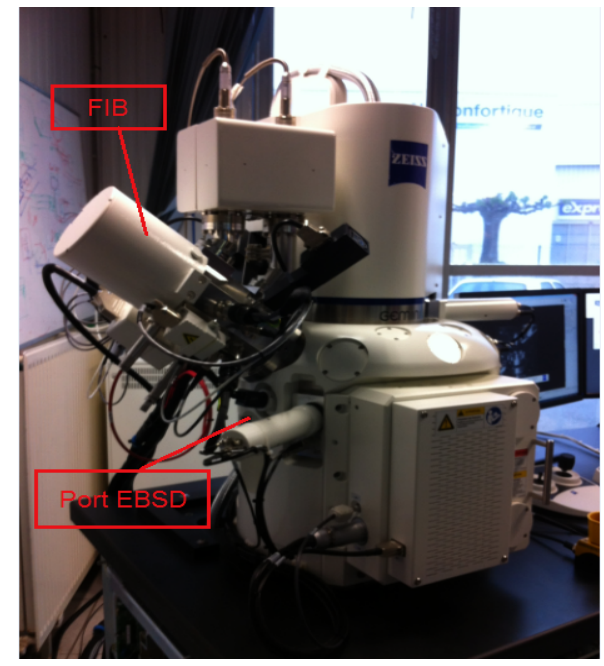

Figure 1. MEB FIB Auriga 40

(a)

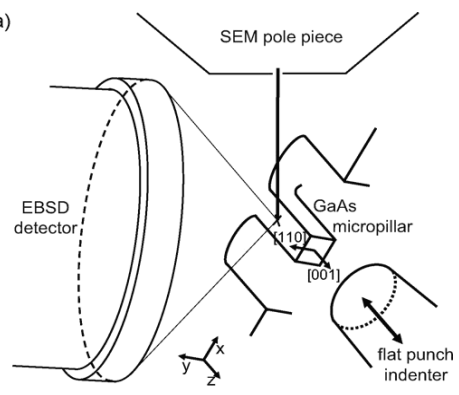

(b)

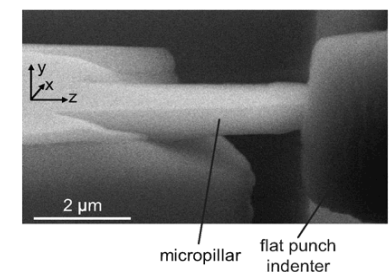

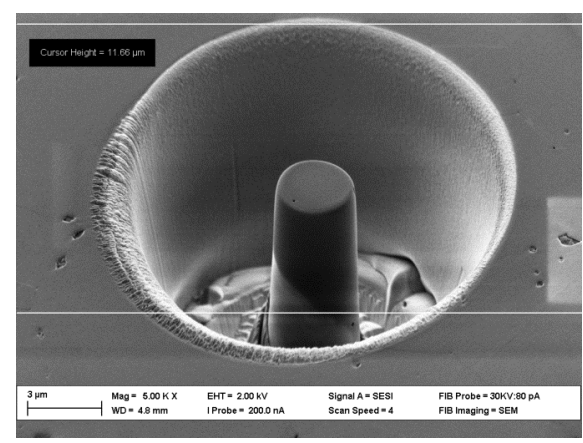

Figure 2. Cubic zirconia pillar manufacturing by FIB

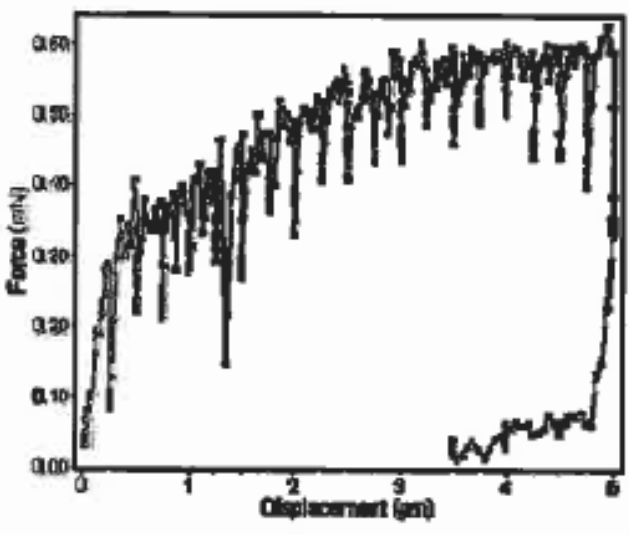

Figure 3. Compression of a micro-pillar. (a) the pillar compression scheme in situ, (b) illustration [2], (c) loading curve versus displacement 